\section{P17 RESPIRATORY IMPACT OF DIABETES MELLITUS IN PEOPLE WITHOUT A PRIMARY DIAGNOSIS OF CHRONIC LUNG DISEASE}

S Ruickbie, A Prasad, PW Jones, EH Baker. St George's, University of London, London, UK

\subsection{6/thoraxjnl-2015-207770.154}

Introduction In the UK, around 3 million people currently have a diagnosis of diabetes mellitus and the prevalence is increasing rapidly. Microvascular and macrovascular complications of diabetes are widely recognised, but the respiratory impact is less well understood. In people with chronic lung disease, diabetes mellitus is associated with worse lung function, impaired health status and more frequent exacerbations (Kinney et al. Diabetes Care. 2014;37:389-95). The aim of our study was to determine the respiratory impact of diabetes in people without a primary diagnosis of chronic lung disease.

Abstract P17 Table 1 Comparison of clinical characteristics, prior respiratory illness, lung function and respiratory symptoms in people with and without diabetes mellitus

\begin{tabular}{|c|c|c|c|}
\hline & $\begin{array}{l}\text { No diabetes } \\
\text { mellitus }\end{array}$ & $\begin{array}{l}\text { Diabetes } \\
\text { mellitus }\end{array}$ & $\begin{array}{l}P \\
\text { value }\end{array}$ \\
\hline \multicolumn{4}{|c|}{ Clinical characteristics } \\
\hline Number & 175 & 75 & \\
\hline Age (years) & $66 \pm 11$ & $67 \pm 9$ & 0.257 \\
\hline Gender ( $(\%)$ female) & $56(32 \%)$ & $22(29 \%)$ & 0.677 \\
\hline Body mass index $\left(\mathrm{kg} / \mathrm{m}^{2}\right)$ & $28.2 \pm 5.7$ & $32.1 \pm 7.7$ & $<0.001$ \\
\hline Waist:hip ratio & $0.94 \pm 0.07$ & $0.97 \pm 0.07$ & 0.001 \\
\hline Blood glucose $\mathrm{mmol} / \mathrm{l}(\mathrm{n})$ & $5.9 \pm 1.7(45)$ & $9.0 \pm 3.2(54)$ & $<0.001$ \\
\hline $\mathrm{HbA}_{1 \mathrm{c}} \mathrm{mmol} / \mathrm{mol}(\mathrm{n})$ & $41 \pm 6(31)$ & $61 \pm 16(29)$ & $<0.001$ \\
\hline \multicolumn{4}{|l|}{ Diabetic medication (n (\%) } \\
\hline None & & $11(15 \%)$ & \\
\hline Oral hypoglycaemics & & $51(68 \%)$ & \\
\hline Insulin ( \pm oral hypoglycaemics) & & $13(17 \%)$ & \\
\hline $\begin{array}{l}\text { Confirmed coronary artery disease } \\
\text { (Gensini }>20 \text { ) }\end{array}$ & $36 \%$ & $42 \%$ & 0.037 \\
\hline Charlson index (excluding diabetes) & $3(2-4)$ & $3(2-4)$ & 0.026 \\
\hline \multicolumn{4}{|c|}{ Smoking history and respiratory illness } \\
\hline \multicolumn{4}{|l|}{ Smoking status (n (\%)) } \\
\hline Never & $41 \%$ & $44 \%$ & 0.873 \\
\hline Ex-smoker & $46 \%$ & $45 \%$ & \\
\hline Current smoker & $13 \%$ & $11 \%$ & \\
\hline Childhood respiratory illness (n (\%)) & $30(17 \%)$ & $18(24 \%)$ & 0.139 \\
\hline On respiratory medication (n (\%)) & $40(23 \%)$ & $16(21 \%)$ & 0.474 \\
\hline Prior COPD diagnosis (n (\%)) & $22(13 \%)$ & $7(9 \%)$ & 0.314 \\
\hline $\begin{array}{l}\text { Prior diagnosis of any chronic lung } \\
\text { disease }(\mathrm{n}(\%))\end{array}$ & $28(16 \%)$ & $18(24 \%)$ & 0.092 \\
\hline \multicolumn{4}{|c|}{ Lung function } \\
\hline $\mathrm{FEV}_{1} \%$ predicted & $83 \pm 21$ & $79 \pm 18$ & 0.134 \\
\hline FVC\% predicted & $91 \pm 22$ & $82 \pm 17$ & 0.002 \\
\hline $\mathrm{FEV}_{1}: \mathrm{FVC}$ & $0.72 \pm 0.11$ & $0.76 \pm 0.09$ & 0.008 \\
\hline \multicolumn{4}{|c|}{ Respiratory symptoms } \\
\hline Breathlessness (mMRC) & $1.7 \pm 0.7$ & $2.1 \pm 0.9$ & 0.001 \\
\hline Cough (/5) & $0.6 \pm 1.1$ & $1.0 \pm 1.3$ & 0.005 \\
\hline Phlegm (/5) & $0.4 \pm 0.9$ & $0.5 \pm 1.0$ & 0.813 \\
\hline Total CAT score & $7 \pm 5$ & $9 \pm 7$ & 0.024 \\
\hline
\end{tabular}

COPD, chronic obstructive pulmonary disease; $\mathrm{FEV}_{1}$, forced expiratory volume in $1 \mathrm{~s}, \mathrm{FVC}$, forced vital capacity; mMRC, modified Medical Research Council dyspnoea scale; CAT, COPD assessment test.

Values are mean $\pm S D$ (compared with independent $t$ tests), median (interquartile range) (compared with Mann Whitney U tests) and number (\%) (compared with chi squared tests).
Methods Unselected patients attending for elective coronary angiography March-July 2015 were invited to take part in a prospective observational study (primary aim to investigate the association between coronary atheroma and airflow obstruction). Participants underwent clinical assessment and spirometry prior to the procedure.

Results 250 of 294 (85\%) people approached took part. Seventy five $(30 \%)$ had diabetes mellitus. People with diabetes were of similar age and gender to those without diabetes, but had greater body mass index, central adiposity, blood glucose and $\mathrm{HbA}_{1 \mathrm{c}}$ (Table 1). Despite no differences in history of smoking or respiratory illness (Table 1), people with diabetes had significantly lower forced vital capacity (FVC) and higher forced expiratory volume $\left(\mathrm{FEV}_{1}\right)$ : FVC ratio than those without diabetes. After adjustment for age, gender, body mass index, waist: hip ratio and smoking history, diabetes was an independent predictor of $\mathrm{FEV}_{1}$ : FVC (partial eta ${ }^{2}$ 0.03, p $=0.007$ ), but not FVC. People with diabetes had more respiratory symptoms (Table 1$)$. They were more likely to give a history of recurrent chest infections (diabetes 14(19\%); no diabetes 11(6\%), $\mathrm{p}=0.004)$ and reported more chest infections (diabetes $0.6 \pm 1.6$; no diabetes $0.2 \pm 0.9, \mathrm{p}=0.007$ ) in the past year. After adjustment for age, waist: hip ratio, body mass index, smoking, $\mathrm{FEV}_{1}$ : FVC and coexisting respiratory disease, diabetes was an independent predictor of recurrent chest infections (odds ratio 2.81 (95\% confidence intervals 1.04-7.73), $\mathrm{p}=0.045)$.

Conclusions Diabetes mellitus is associated with worse lung function, increased respiratory symptoms and more frequent chest infections, independent of smoking and prior respiratory illness. The burden of diabetes-associated respiratory disease on patients and the NHS is likely to increase as diabetes becomes more prevalent.

\section{P18 THE EFFECTS OF ACUTE AND REPEATED BOUTS OF UNILATERAL NEUROMUSCULAR ELECTRICAL STIMULATION ON QUADRICEPS MUSCLE INFLAMMATION IN COPD}

${ }^{1} \mathrm{~A}$ Gray, ${ }^{1} \mathrm{~L}$ Latimer, ${ }^{1} \mathrm{~A}$ Parmar, ${ }^{1} \mathrm{P}$ Bradding, ${ }^{1} \mathrm{NJ}$ Greening, ${ }^{2} \mathrm{MC}$ Steiner. ${ }^{1}$ University of Leicester, Leicester, UK; ${ }^{2}$ University Hospitals of Leicester, Leicester, UK

\subsection{6/thoraxjnl-2015-207770.155}

Introduction and objectives Impaired skeletal muscle function is an important systemic manifestation of COPD which can be improved by exercise training. Non-volitional training using neuromuscular electrical stimulation (NMES) may be an effective training technique in situations where voluntary exercise may be difficult or impractical (e.g. peri-exacerbation or severe ventilatory limitation). Exercise is known to result in both intramuscular and systemic inflammation. However, the cellular response to NMES, which directly depolarises the motor units, is unclear. We investigated the impact of acute and repeated bouts of unilateral NMES in COPD patients.

Methods 16 patients underwent 6 weeks of unilateral NMES 5 times a week for $30 \mathrm{~min}$ at $50 \mathrm{~Hz}$ at Glenfield Hospital, Leicester. Mean (SD) age was 65 (9) years, $\mathrm{FEV}_{1}$ : 50 (22)\% predicted, BMI $26.5(5.2) \mathrm{Kg} / \mathrm{m}^{2}$ ). Isometric quadriceps strength, regional muscle mass (DEXA) and quadriceps thickness (ultrasound) were recorded at baseline and at the end of the intervention. Vastus lateralis muscle biopsies were obtained from both the trained and untrained limbs at baseline, $24 \mathrm{~h}$ after the first bout of NMES and at 6 weeks. Venous blood was taken at the same 